\title{
Р.Ю. Волоснов
}

\section{СЕЛЬСКИЙ ПРАВОСЛАВНЫЙ ХРАМОВЫЙ КОМПЛЕКС АЛТАЯ КОНЦА ХІХ - НАЧАЛА ХХ В. (ПЛАНИРОВКА И ФУНКЦИОНАЛЬНОСТЬ ЭЛЕМЕНТОВ)}

\begin{abstract}
В статье рассматриваются планировочная структура и функциональность как основных, так второстепенных элементов сельских храмовых комплексов Алтая дореволюционного периода (икольных зданий, сторожек, различных хозяйственных и богослужебных построек, декоративных элементов и объектов мемориального значения) и предпринята попытка их систематизации. Также затронуты аспекты многофункциональности и дублирования основных составляющих православных церковных комплексов и ансамблей, показано их хозяйственное, просветительское, эстетическо-гармонизирующее влияние на развитие алтайского села.
\end{abstract}

Ключевые слова: православие, храмовый комплекс, Алтай, конец XIX-начало XX в.

Православный храмовый комплекс представляет собой совокупность множества элементов, где главным и связующим звеном является церковь. Разнообразные архитектурные элементы храмовых комплексов эстетично и функционально взаимосвязаны и образуют единую гармоничную среду. Центральные ансамбли дореволюционных сел состояли из множества зданий: церкви, отдельно стоящие колокольни, школы, причтовые дома, приходские школы, «крещальни», церковные лавки и др. Границы сельских православных храмовых комплексов необязательно обозначались нахождением элементов внутри церковной ограды. Разнообразные архитектурные здания, имеющие отношение к церковной усадьбе, могли размещаться и за оградой, одновременно включаясь в храмовый ансамбль.

Под термином «Алтай» имеется в виду территория Алтайского горного округа. В исследуемый период в нее входили территории современных Алтайского края (полностью), Республики Алтай (полностью) и югозападная часть Республики Хакасия; большая часть Кемеровской, южная и восточные части Новосибирской и южная - Томской областей; а также северо-восточные области Казахстана. Основными источниками для написания работы послужили заметки и статьи издания «Томские епархиальные ведомости»- официального церковного печатного издания, выходившего с лета 1880 до конца 1917 г., редакция которого состояла при Томской духовной семинарии. Материалы данного источника, несмотря на сугубо официальный статус, позволяют критично вычленить и проследить все сложности и преимущества планировочного размещения, а также функциональности большинства элементов храмового комплекса. Фактические данные о сельских храмовых комплексах представлены в равной степени из различных природно-географических и административных районов Алтая. 
В целом многообразие элементов сельских православных храмовых комплексов Алтая конца XIX - начала XX в. можно систематизировать на основе их функциональной составляющей:

1) Помещения богослужебного назначения (церкви, часовни, «крещальни» и др.). Центральные здания храмовых комплексов - собственно церкви - являлись, по сути, единственными функционально и планировочно неизменными элементами ввиду их сакрального статуса (только культовая деятельность и расположение в центре комплекса). В свою очередь, часовни и «крещальни» как вспомогательный богослужебный элемент часто устраивали в крупных приходах в непосредственной близости от храмов. Наличие часовен в храмовых комплексах могло зависеть от процессов перестроения других строительных объектов (строительство более вместительных храмов или школ). К примеру, бывший священник Тяжинского прихода Нешумов «...расположил прихожан к устройству училища. Для помещения училища была перенесена в церковную ограду часовня, стоявшая вне я. Обществом, употреблено было на эту постройку более 100 р., из коих 50 р. были собраны по подписке. Строителем училища и расходчиком этих денег был церковный староста Николай Ожигов...» [1. С. 19]. Кроме этого, помещения богослужебного предназначения могли иметь и мемориальный статус, прежде всего часовни. Также, помимо часовен, отражающих в большинстве своем то или иное символическое событие, в сельских православных храмовых комплексах могли находиться и другие мемориальные объекты (кресты, захоронения и др.). Установка памятных и поклонных крестов внутри храмовых комплексов носила символический характер. Как правило, они обозначали места закладки новых более вместительных храмов или месторасположение бывшей, старой, церкви.

Таким образом, помещения богослужебного значения имели сакральный характер (в первую очередь собственно церкви) и использовались сугубо по назначению, а некоторые из них могли носить мемориальный характер (часовни).

2) Служебно-бытовые помещения (сторожки, причтовые дома). Первоначальное и главное предназначение церковных сторожек традиционно состояло в выполнении функции охраны храмов посредством несения караульной службы церковных сторожей в ночное и внебогослужебное время суток. C конца XIX в. в большинстве сел Алтая церковные сторожки стали устраивать как отдельные здания, венчающие вход в храмовый комплекс. Несмотря на свою непосредственную узкую функциональность (месторасположение сторожа, ведущего наблюдение за охраной церкви), сельские церковные сторожки конца XIX - первой трети XX в. представляли собой сравнительно обширные и объемные сооружения, что часто использовалось настоятелями храмов и церковными старостами для временного исполнения функций других объектов храмовых комплексов. Связано это было в первую очередь с низкими экономическими возможностями приходов, которые не имели средств на устройство отдельных специализированных зданий (в первую очередь школ). К примеру, в с. Хлопуновском при церкви Трех Святителей школа была открыта 13 января 1887 г. и помещалась в церковной сторожке, приспособленной к такого рода деятельности. «...Помещение довольно про- 
сторное, теплое, светлое и для школы удобное. В школе обучалось 23 мальчика и 7 девочек, обучает в школе диакон Константин Иконников...» [2. С. 5-17]. В целом здания церковных сторожек имели важное композиционное значение в ансамбле сельских храмовых комплексов Алтая, будучи наряду с церковной оградой границей между территорией храма и светским миром, и также являлись многофункциональными объектами, которые заменяли другие элементы храмового комплекса (школы, библиотеки, дома священнослужителей и др.).

Также примером гармоничного включения в храмовый ансамбль сельских комплексов Алтая можно отнести здания школьных общежитий. Наиболее часто общежития при школах устраивали в миссионерских или с большим количеством инородческого населения приходах. В с. Марзагуль (ныне райцентр Михайловское Алтайского края) при открытии киргизского отделения в церковной школе обязательно планировалось строительство общежития «...на 15-20 человек, чтобы в общежитие это могли помещать детей киргизы из отдаленных аулов. Расход на общежитие будет незначительный: рублей 35-40 в год на плату кухарке и рублей 20 на отопление; содержание у киргизов-пансионеров будет свое...» [3. С. 26]. Показателен пример Новогеоргиевской второклассной школы Змеиногорского уезда (современной райцентр Новоегорьевское Алтайского края), где здания общежитий в 1910 г. состояли из спальни для учеников на 21 койко-место, столовой, кухни, прачечной и других объектов [4. С. 503].

Немаловажную роль в ансамбле храмовых комплеков играли дома священноцерковнослужителей. Сельский православный причт в большинстве своем состоял из священника и псаломщика, для которых обязательно требовались дома в непосредственной близости от церкви. Технология их строительства в целом являлась традиционной, как и для других жилых сооружений. Обязательным условием строительства домов для духовенства было устройство на каменном фундаменте. Причтовый дом священника с. Елбанское (современное с. Елбанка Усть-Пристанского района Алтайского края) в начале XX в. представлял собою «простой крестьянский дом, построенный местным крестьянином для своей надобности. Длина его 10 1/4 аршин, ширина 7 1 2 аршин, высота комнат в верхнем этаже 3 аршина, а в нижнем 2 1/2 аршина, а от матки-бревна только 2 1/4 аршина. Под матку сделана подставка столб, так как один конец ея от времени надломился» [5. С. 1272]. По композиционному местоположению, преследуя в первую очередь прагматические функции, причтовые дома находились в прямой близости от храмов. Финансовая состоятельность, степень религиозности, численный и конфессиональный состав приходов также могли влиять на размеры, убранство и внутреннюю планировочную структуру причтовых домов. На полную обеспеченность причта домами влиял иерархический аспект. Часто в сельских приходах приоритетным моментом для крестьян являлось обеспечение жильём в первую очередь священника, а на дома для диаконов и псаломщиков у них часто не оставалось средств, времени и особого желания, что в свою очередь приводило к самостоятельному поиску мест проживания (квартирование). Показателен пример описания проблематичной ситуации с состоянием причтовых домов в 1904 г. в с. Красноярское (современный Поспелихинский район Алтайского края). 
«...Причтовыя помещения, хотя и есть для всех членов причта, но дома священников пришли в крайнею ветхость, прихожане не хотят ремонтировать их, ходатайствуя о сокращении штата, так как ремонтировка домов непосильна для них. В зимнее время дома для причта холодны настолько, что в ветры и морозы семьи священников спасаются только железными печами...» [6. С. 46]. В приходах с проживанием старообрядцев обеспеченность причтовых домов в связи с нежеланием населения участвовать в православной церковно-приходской жизни также была минимальной. Таким образом, дома священноцерковнослужителей являлись важными элементами ансамблей и храмовых комплексов сел Алтая в конце XIX - начале XX в. Они гармонично вписывались в практическую и эстетическую составляющую объектов храмовой инфраструктуры. Наличие причтовых домов в селе показывало степень религиозности населения, экономическую стабильность и дальнейшую перспективу развития населенного пункта.

Служебно-бытовые помещения сельских храмовых комплексов Алтая конца XIX - начала XX в., несмотря на первостепенную функциональность, из-за низкого финансового состояния приходов часто использовались в контексте других предназначений, в первую очередь просветительских (использование церковных сторожек под нужды школ).

3) Помещения просветительской деятельности (школы, библиотекичитальни, книжные лавки и др.). Важную композиционную основу занимали церковно-приходские школы или здания, в которых они функционировали. Школы могли располагаться непосредственно в церковной ограде или вблизи церкви. Часто такие архитектурные элементы, как школы, из-за тесноты общей площади комплекса могли устраиваться впритык или в одной связи с другими приходскими объектами. К примеру, в с. Верх-Ануйское Бийского уезда (современный Быстроистокский район Алтайского края) в конце XIX в. торгующие местные крестьяне построили за свой счет приписную церковь, а также «сочувствуя школе построили крестовый (в 4 комнаты) дом при церкви». В одной комнате этого дома помещалась сторожка, «имея особый ход для себя, а в двух комнатах с прихожею» школа [7. С. 16-17].

В конце XIX в. епархиальные власти в целях повышения духовнонравственного уровня населения всячески пытались стимулировать открытие в сельских приходах бесплатных библиотек-читален и «чайных», которые располагались либо в специализированных зданиях при школах, либо вблизи располагавшихся наемных помещений. В 1902 г. с. Старо-Белокурихинское Бийского уезда (ныне Алтайский район Алтайского края) при местном церковном обществе трезвости вблизи церкви были открыты «чайная и читальня», помещавшиеся в наемном здании из двух комнат [8. С. 33]. Помимо открытия специализированных библиотечных зданий, епархиальными властями рекомендовалось устраивать в храмовых комплексах передвижные библиотеки и так называемые «библиотеки-фонари», в которые под стекло вставлялись книжные листы. Они устраивались на невысоких столбах в церковной ограде, как правило, возле школ. Безусловную пользу, эстетичность и практичность таких конструкций священнослужители объясняли следующим образом: «...прихожане, имея обыкновение приходить в церковь или на беседу ранее назначеннаго времени, чтобы не проводить время в пустых разговорах, 
будут иметь возможность почитать лист или брошюрку. Библиотекифонари - устраиваются многогранные, что даст возможность читать как одному грамотею, так и более 8-10, если в толпе найдется несколько грамотных...» [9. С. 55]. Также в многочисленных приходах и при больших церковно-школьных библиотеках в храмовых комплексах могли устраиваться специальные здания книжных складов. В сельских приходах, где причт всецело озадачивался вопросами религиозности и просвещения, на территории храмовых комплексов находились специализированные здания для продажи книг. Также на территориях храмовых комплексов устраивались и нефиксированные, передвижные книжные лавки. К примеру, в 1909 г. при Таловском Михаило-Архангельском приходе (ныне Змеиногорский район Алтайского края) «...для постоянных чтений и частных собеседований по домам поставлено открыть библиотеку, читальню и книжную лавку, для чего собрано около 70 рублей, преступлено к составлению списков-книг, газет и журналов, подлежащих к выписке для дела...» [10. С. 7]. Показателен еще один пример. 13 октября 1898 г. в с. Николаевское благочиния № 36 (ныне Поспелихинский район Алтайского края) был доставлен шкаф с разными книгами для продажи жителям. На шкафу была помещена подпись: «Книжная лавка П.И. Макушина, открыта с благословления Преосвященнаго Макария, Епископа Томскаго и Барнаульскаго». Сам шкаф помещался в «сборной избе», продажей книг, по поручению Курьинского волостного правления, заведовал сельский писарь Поповских, человек «трезвый и честный» [11. С. 24-25].

Таким образом, среди всех помещений просветительской деятельности в сельских храмовых комплексах Алтая означенного периода выделяются школьные здания, а в наиболее обеспеченных или многочисленных приходах помещения, связанные с библиотечной деятельностью или с продажей книг.

4) Помещения и объекты хозяйственной деятельности. Наибольшим многообразием сельские православные храмовые комплексы Алтая в означенный период изобиловали именно постройками хозяйственного предназначения. Можно выделить следующие основные виды:

а) заводы (свечные. кирпичные и др.). В сельских приходах и храмовых комплексах с развитой хозяйственной деятельностью часто сооружались мини-заводы. Кирпичные заводы часто устраивались непосредственно для возведения каменных церквей ввиду отсутствия леса в том или ином селении. Примером может служить планирование устройства в 1913 г. кирпичного завода и церкви в Тарабинском стане Алтайской духовной миссии (ныне с. Улус Тараба Кытмановского района Алтайского края). Для приобретения денежных средств на эту цель жителями улуса решено было осуществить общественную запашку 40 десятин лучшей земли [13. С. 516]. Однако по материальным причинам каменное храмостроительство не стало распространенным на территории деятельности Алтайской миссии [14. С. 185]. Свечные заводы в сельской местности Алтая преимущественно устраивались при монастырях (Бийский Тихвинский женский монастырь);

б) хозяйственно-ремесленные пристройки к иколам. По распоряжению Святейшего Синода с начала 1890/91 учебного года при главнейших церковно-приходских школах были открыты специальные ремесленные классы, причем первое время в этих классах ученики обучались производству раз- 
личных изделий из дерева, а впоследствии другим ремеслам (к примеру, книжные переплетные мастерские). Часто для такого рода ремесленных классов устраивались отдельные здания-мастерские или пристраивались особые помещения. К примеру, обширный церковно-школьный комплекс Покровской церкви с. Тоурак Бийского уезда (ныне Алтайский район Алтайского края) включал: зал для праздничных и народных чтений, две классные комнаты, читальню, библиотеку с музеем, учительскую комнату, метеорологическую станцию, склад усовершенствованных сельскохозяйственных машин, сторожку и столярно-переплетную мастерскую, помещавшуюся в особой комнате. Данная ремесленная мастерская располагала десятью верстаками с соответствующим набором главнейших столярных инструментов и 30 штуками переплетных инструментов [15. С. 23];

в) просфорни и хлебозапасные амбары. Важнейшим элементом богослужебной деятельности православных храмов и монастырей является приготовление специальных хлебов - просфор. Нередко просфорни располагались в зданиях храмовых комплексов с совмещенными функциями (в сторожках, трапезных, нижних ярусах колоколен), но также для них устраивались отдельные здания. В сельской местности Алтая начала XX в. примером может служить Александро-Невский скит близ с. Жуланиха (современный Заринский район Алтайского края), где в 1914 г. было построено отдельное здание для просфорни [13. С. 167]. Наибольшего распространения в селах Алтая такого рода хозяйственная деятельность получила в 10-е гг. XX в. Также отдельными элементами храмовых комплексов хозяйственного предназначения являлись здания амбаров. Показателен пример хозяйственной деятельности священника и прихожан с. Старая Чемровка Бийского уезда (ныне Бийский район Алтайского края) в начале XX в.: «...По совету и настоянию о. Иннокентия (Емельянова. - P.B.), крестьяне завели общественную запашку земли с тем, чтобы доход от запашки поступал на приходские нужды... Полученный от урожая хлеб ссыпали в особо-устроенный церковный амбар. К 1900-му году хлеба в этом амбаре накопилось довольно много. Как раз случился неурожай и голод, и крестьяне начали бедствовать. Отец Иннокентий отложил на время заботы о постройке храма и весь хлеб раздал нуждающемуся населению... Голод миновал, наступили урожайные года, крестьяне с благодарностью возвратили занятый из церковнаго амбара хлеб. Хлеб этот был выгодно продан, и вот на вырученныя от продажи этого хлеба деньги, по преимуществу, и выстроены в Старой Чемровке церковь, школа и дом священника...» [16. С. 24-25];

г) объекты пчеловодческой отрасли. В течение всего рассматриваемого периода епархиальные власти всячески стимулировали развитие пчеловодческой отрасли под эгидой церкви, в связи с этим в сельские храмовые комплексы добавлялись инфраструктурные элементы, связанные с данной деятельностью. Часто на территории школьных садов и огородов, которые можно считать гармоничным продолжением общего церковного комплекса, устраивались опытные производственные пасеки, где школьники изучали основы пчеловодства. При Тогульской второклассной церковной школе Кузнецкого уезда (современный райцентр Алтайского края) в 1906 г. недалеко от школы находилась показательная пасека, пайщиком которой состояла школа, 
благодаря чему ученики имели возможность познакомиться с рациональным ведением пчеловодства [17. С. 389-390]. Во времена Первой мировой воины томские епархиальные власти активно начали организовывать строительство помещений для производства воска в сельской местности - воскобоен. В частности, на совещании членов Епархиального Пчеловодческого комитета при Томском свечном заводе в своем журнале собрание указало следующие населенные пункты в границе современного Алтайского края, признанные удобными для устройства воскобоен: села Тогульское и Быстрый Исток и Колыванский завод [18. С. 48].

Таким образом, многочисленные элементы сельских православных храмовых комплексов Алтая конца XIX - начала XX в. выполняли разнообразные, взаимно заменяющиеся и дублирующие функции (культовые, хозяйственные, просветительские, мемориальные и др.). В свою очередь полифункциональность главных элементов в меньшей степени распространялась на собственно культовые сооружения в связи с их сакральным статусом. Границы сельских православных храмовых комплексов необязательно обозначались нахождением элементов внутри церковной ограды. Разнообразные хозяйственные и другие здания, имеющие отношение к церковной усадьбе, могли размещаться и за оградой, одновременно включаясь в храмовый ансамбль.

\section{Литература}

1. Свящ. Коронатов. Летопись села Тяжинскаго Николаевской церкви (Мариин. окр.). Отдел неофициальный // Томские епархиальные ведомости. 1898. № 11 (1 июня). С. 11-19.

2. Карпов А. Священник о. Иоанн Цеба. (Некролог) II. Отдел общецерковный. Часть неофициальная // Томские епархиальные ведомости. 1913. № 18 (15 сент.). С. 1037-1040.

3. Об училищах при церквах. Сведения о состоянии церквей, духовенства и прихожан, состоящих в благочинии № 26 за 1891 год. Продолжение. Отдел неофициальный // Томские епархиальные ведомости. 1892. № 15 (1 авг.) С. 16-17.

4. Из области церковно-школьной жизни. Отдел неофициальный // Томские епархиальные ведомости. 1901. № 4 (15 февр.) С. 24-27.

5. Отчет Томского Епархиального наблюдателя о состоянии церковных школ Томской епархии в учебно-воспитательном отношении за 1908-1909 учебный год. (Продолжение). Официальная часть // Томские епархиальные ведомости. 1910. № 18 (15 сент.). С. 497-509.

6. Село Елбанское Бийского уезда Томской губернии. Происхождение старообрядчества. II. Отдел общецерковный. Часть неофициальная // Томские епархиальные ведомости. 1912. № 22 (15 нояб.). С. 1269-1272.

7. Новиков И. Летняя поездка Его Преосвященства, Преосвященнейшего Макария, Епископа Томского и Барнаульского, для обозрения епархии с 17-го июня по 26 июля 1904 года. (Продолжение) II Отдел. Неофициальная часть // Томские епархиальные ведомости. 1904. № 22 (15 нояб.). С. 40-46.

8. К вопросу о церковно-приходских школах. Отдел официальный // Томские епархиальные ведомости. 1887. № 12 (15 июня). С. 16-17.

9. Отчет о Покровском церковно-приходском Обществе трезвости села СтароБелокурихинского за 1902 год. Неофициальный отдел // Томские епархиальные ведомости. 1903. № 11 (1 июня). С. 32-35.

10. Смирнов П. Собрание духовенства градо-Барнаульских церквей и о.о. благочинных Барнаульского уезда 16 Июля 1905 года. II Отдел. Протокол № 3-й. Неофициальная часть // Томские епархиальные ведомости. 1905. № 19 (1 окт.). С. 50-57.

11. Рапорт Его Преосвященству, Высокопреосвященнейшему Макарию, Архиепископу Томскому и Алтайскому. Официальная часть // Томские епархиальные ведомости. 1909. № 1 (1 янв.). С. 7-8. 
12. Из иерковной летописи с. Николаевского, благочиния № 36-го. Отдел неофициальный // Томские епархиальные ведомости. 1899. № 7 (1 апр.). С. 21-25.

13. Отчет Алтайской Духовной миссии за 1913-й год. (Продолжение). І. Отдел миссионерский. Часть неофициальная // Томские епархиальные ведомости. 1914. № 8-9 (1 мая). C. 511-528.

14. Крейдун Ю.А. Миссионерское храмоздательство на Алтае. Воссоздание облика утраченных храмов XIX - начала XX в. Барнаул : Алт. дом печати, 2013. 362 с.

15. Покровское приходское попечительство в 1899 г. (Продолжение). Отдел неофициальный // Томские епархиальные ведомости. 1900. № 10 (15 мая). С. 20-25.

16. Священник о. Иннокентий Емельянов. Неофициальная часть // Томские епархиальные ведомости. 1905. № 13 (1 июля). С. 24-27.

17. Мироносицкий B. Отчет Томского Епархиального наблюдателя о состоянии церковных школ Томской епархии в учебно-воспитательном отношении за 1910-1911 учебный год. (Окончание). Часть официальная // Томские епархиальные ведомости. 1912. № 16 (15 авг.). C. 389-390.

18. Совещание членов Епарх. Пчеловодного комитета при Томском свечном заводе. Хроника. Пчела и воск // Томские епархиальные ведомости. 1916. № 3 (1 февр.). С. 47-48.

Volosnov Roman U. Altai State University (Barnaul, Russian Federation).

E-mail: volosnov-barnaul@mail.ru

Tomsk State University Journal of Cultural Studies and Art History, 2017, № 26, pp. 140-148.

DOI: $10.17223 / 22220836 / 26 / 15$

THE RURAL ORTHODOX TEMPLE COMPLEX OF ALTAI OF THE END XIX - THE BEGINNING OF THE XX-th CENTURIES (PLANNING AND FUNCTIONALITY OF ELEMENTS) ries.

Key words: Orthodoxy, temple complex, Altai, the end of XIX - the beginning of the XX centu-

The orthodox temple complex represents set of a set of buildings and constructions the main thing and a link which the church is. The central ensembles of pre-revolutionary villages consisted of a set of buildings, the being main elements of temple complexes: churches, separate belltowers, priest houses, parish schools, church sentries building. Also special binding place in church complexes was taken by minor, additional elements the carrying-out various functions. Schools of spiritual department and the building at which they functioned occupied one of the main composite places in ensemble of temple complexes and were the prevailing components of these complexes, regardless of that there was a building for schools within a church fencing or in close proximity. Buildings church сторожек also occupied important composite value in ensemble of rural temple complexes of Altai, being along with a church fencing - border between the territory of the temple and the secular world, and were multipurpose objects which replaced other elements of the temple complex (school, library, the house of priests). Houses of sacred clergymen were important elements of ensembles and temple complexes of the villages of Altai at the end of XIX - the beginning of the 20th centuries. They harmoniously fitted into a practical and esthetic component of objects of temple infrastructure. Availability the priest of houses in the village showed degree of religiousness of the population, economic stability and further prospect of development of the settlement. Minor elements of rural orthodox temple complexes of Altai of the end XIX - the beginning of the 20th centuries carried out various functions (cult, economic, educational memorial, etc.) also were mainly specifics of large rural settlements, or the receipts which were actively engaged in various economic activity. Also much important role in distribution of minor elements of temple complexes extent of statement of church and school case influenced. The landscape gardening construction in rural temple complexes of Altai of the end of the XIX-XX century was the traditional estetiko-harmonizing element and had two functional components: economic and practical (mainly school gardens) and esthetic (gardens near temples). Thus, numerous elements of rural orthodox temple complexes of Altai of the end XIX - the beginning of the 20th centuries carried out the various, mutually replaced and duplicative functions (cult, economic, educational, memorial) and borders of rural orthodox temple complexes were optionally designated by finding of elements in a church fencing. The various economic and other buildings concerning the church estate could be placed and behind a fencing, at the same time joining in temple ensemble. 


\section{References}

1. Koronatov. (1898) Letopis' sela Tyazhinskago Nikolaevskoy tserkvi (Mariin. okr.) [The chronicle of the Tyazhinskoe village, Nikolayev Church (Mariinsk District)]. Tomskie eparkhial'nye vedomosti. 1st June. pp. 11-19.

2. Karpov, A. (1913) Svyashchennik o. Ioann Tseba. (Nekrolog) [Priest Father Ioann Tseba. (Obituary)]. Tomskie eparkhial'nye vedomosti. 15th September. pp. 1037-1040.

3. Anon. (1892) Ob uchilishchakh pri tserkvakh. Svedeniya o sostoyanii tserkvey, dukhovenstva i prikhozhan, sostoyashchikh v blagochinii № 26 za 1891 god. Prodolzhenie [About parochial schools. Information about the state of churches, clergy and parishioners of Deanery No. 26 for 1891. Continuation]. Tomskie eparkhial'nye vedomosti. 1st August. pp. 16-17.

4. Anon. (1901) Iz oblasti tserkovno-shkol'noy zhizni [From parochial school life]. Tomskie eparkhial'nye vedomosti. 15th February. pp. 24-27.

5. Anon. (1910) Otchet Tomskogo Eparkhial'nogo Nablyudatelya o sostoyanii tserkovnykh shkol Tomskoy eparkhii v uchebno-vospitatel'nom otnoshenii za 1908-1909 uchebnyy god [Report of the Tomsk Diocesan Observer on the state of church schools in Tomsk Diocese in terms of education for 1908-1909]. Tomskie eparkhial'nye vedomosti. 15th September. pp. 497-509.

6. Anon. (1912) Selo Elbanskoe Biyskogo uezda Tomskoy gubernii. Proiskhozhdenie staroobryadchestva [The Elbanskoe village of Biysk district, Tomsk Province. The origin of the Old Believers]. Tomskie eparkhial'nye vedomosti. 15th November. pp. 1269-1272.

7. Novikov, I. (1904) Letnyaya poezdka Ego Preosvyashchenstva, Preosvyashchenneyshego Makariya, Episkopa Tomskogo i Barnaul'skogo, dlya obozreniya eparkhii s 17-go iyunya po 26 iyulya 1904 goda [The summer trip of His Eminence, His Grace Makarii, Bishop of Tomsk and Barnaul, to view the diocese from 17 June to 26 July, 1904]. Tomskie eparkhial'nye vedomosti. 15th November. pp. 40-46.

8. Anon. (1887) K voprosu o tserkovno-prikhodskikh shkolakh [On parochial schools]. Tomskie eparkhial'nye vedomosti. 15th June. pp. 16-17.

9. Anon. (1903) Otchet o Pokrovskom tserkovno-prikhodskom Obshchestve trezvosti sela StaroBelokurikhinskogo za 1902 god [Report on the Pokrovskoe Parochial Society of sobriety in StaroBelokurikhinskoe for 1902]. Tomskie eparkhial'nye vedomosti. 1st June. pp. 32-35.

10. Smirnov, P. (1905) Sobranie dukhovenstva grado-Barnaul'skikh tserkvey i o.o. blagochinnykh Barnaul'skogo uezda 16 Iyulya 1905 goda [Meeting of the clergy of Barnaul churches and Barnaul Uyezd on July 16, 1905]. Tomskie eparkhial'nye vedomosti. 1st October. pp. 50-57.

11. Anon. (1909) Raport Ego Preosvyashchenstvu, Vysokopreosvyashchenneyshemu Makariyu, Arkhiepiskopu Tomskomu i Altayskomu [Report to His Eminence Makarii, Archbishop of Tomsk and Altai]. Tomskie eparkhial'nye vedomosti. 1st January. pp. 7-8.

12. Anon. (1899) Iz tserkovnoy letopisi s. Nikolaevskogo, blagochiniya № 36-go [From the church chronicle. Nikolaevskoe Village, Deanery No. 36]. Tomskie eparkhial'nye vedomosti. 1st April. pp. 21-25.

13. Anon. (1914) Otchet Altayskoy Dukhovnoy Missii za 1913-y god [Report of the Altai Spiritual Mission for 1913]. Tomskie eparkhial'nye vedomosti. 1st May. pp. 511-528.

14. Kreydun, Yu.A. (2013) Missionerskoe khramozdatel'stvo na Altae. Vossozdanie oblika utrachennykh khramov XIX - nachala XX v. [Missionary temple-building in Altai. Reconstruction of the lost temples of the 19th - early 20th centuries]. Barnaul: Alt. dom pechati.

15. Anon. (1900) Pokrovskoe prikhodskoe popechitel'stvo v 1899 g. [Pokrovskoe village parish guardianship in 1899]. Tomskie eparkhial'nye vedomosti. 15th May. pp. 20-25.

16. Anon. (1905) Svyashchennik o. Innokentiy Emel'yanov [Priest Father Innokentiy Yemelyanov]. Tomskie eparkhial'nye vedomosti. 1st July. pp. 24-27.

17. Mironositskiy, V. (1912) Otchet Tomskogo Eparkhial'nogo Nablyudatelya o sostoyanii tserkovnykh shkol Tomskoy eparkhii v uchebno-vospitatel'nom otnoshenii za 1910-1911 uchebnyy god [Report of the Tomsk Diocesan Observer on the state of the church schools in Tomsk Diocese in terms of education for 1910-1911 academic year]. Tomskie eparkhial'nye vedomosti. 15th August. pp. 389-390.

18. Anon. (1916) Soveshchanie chlenov Eparkh. Pchelovodnogo komiteta pri Tomskom svechnom zavode. Khronika. Pchela i vosk [Meeting of members of the Dioceses of the Beekeeping Committee at the Tomsk Candle Factory. The Chronicle. Bee and Wax]. Tomskie eparkhial'nye vedomosti. 1st February. pp. 47-48. 